\title{
The predictive value of self assessed general, physical, and mental health on functional decline and mortality in older adults
}

\author{
Yunhwan Lee
}

\begin{abstract}
Objective-To examine the extent to which older people's self assessments of general health, physical health, and mental health predict functional decline and mortality. Design-The study uses population-based secondary data from the US Longitudinal Study of Aging (LSOA).

Participants-A total of 7527 persons aged 70 years or above living in the community. Methods-Eight different measures on self reported general, physical, and mental health were used. Change in functional status was measured using a composite index of ADLs and IADLs over a period of six years. Duration of survival was calculated over a period of seven years. Adjusting for age and gender, multiple logistic regression was used in analysing functional decline, and Cox proportional hazard model, for mortality. Then all of the self assessed health measures were incorporated into the final model-controlling for baseline sociodemographic characteristics, functional status, disease/ conditions, and use of health and social services-to assess the independent contribution of each measure in predicting future health outcomes.
\end{abstract}

Main results-Overall, older people's self assessed general, physical, and mental health were predictive of functional decline and mortality. In multivariate analyses, older people who assessed their global health, self care ability, and physical activity less favourably were more likely to experience poor health outcomes. Gender disparity, however, was observed with poor global health affecting functional decline in men only. Self care ability was predictive of functioning in women only, whereas it was predictive of mortality in men only.

Conclusions-Self assessed global health, as well as, specific dimensions of health act as significant, independent predictors of functioning and mortality in a community dwelling older people.

(F Epidemiol Community Health 2000;54:123-129)

Preventive Medicine,

Ajou University School

of Medicine, Wonchon

Dong 5, Pardar Gu,

Suwon 442-749, South

Korea

Correspondence to:

Dr Y Lee

Accepted for publication 16 June 1999 two, with unfavourable assessment of overall health being associated with increased risk of death, even after controlling for socioeconomic status, physical health, functioning, chronic conditions, and health risk behaviours. ${ }^{1-7}$ There are suggestions, however, that the predictive value of global self rated health on mortality may not be uniform across all population groups, as variations have been noted in the strength or significance of the association by specific age and gender subgroups. ${ }^{8-12}$ Accumulating evidence also indicates poor global self rated health to be predictive of decline in functioning over time. ${ }^{413-15}$

Studies examining the predictive role of self assessed health, in large part, have used a single item global rating of health that is measured by variants of the question, "How would you rate your own health, compared to others of your age?" Relatively few research, however, have examined the predictive value of subjective ratings of specific health domains, such as physical and mental health, besides overall health. Recent studies suggest that these specific health perceptions may also have some predictive value. In a study by Wolinksy, Stump, and Clark, ${ }^{16}$ elderly people's report of physical activity and exercise was found to be related to better health outcomes - in terms of mortality, hospitalisation, nursing home placement, and changes in functional status. Self rated functional ability, defined as the ability to take care of oneself, also strongly predicted functional decline ${ }^{17}$ and death. ${ }^{17}{ }^{18}$

Self perception of specific health domains does not seem to be equivalent to that of overall health. Kempen et $a l^{19}$ reported that less than half of the variance of single item measure of global self rated health was explained by domain specific health measures. Although correlation between single item overall health and specific health dimensions is moderate to high, this does not mean that both concepts are the same and thus exchangeable. ${ }^{20}$ The effect of specific health assessments on health outcomes may be different from that of overall health ratings.

In this study, three dimensions of self assessed health - general, physical, and mental health - are examined to identify major predictors of functional decline and mortality in older adults. By incorporating self ratings of various health domains into a model that predicts future health outcomes, independent contribution of each measure can be identified. The Longitudinal Study of Aging (LSOA) provides a unique opportunity to study the influence of perceptions of various health dimensions on 
future health outcomes among the community dwelling elderly.

\section{Methods}

DATA

The LSOA is based on a sample frame of Supplement of Aging (SOA) to the 1984 National Health Interview Survey (NHIS) that includes 7527 community dwelling participants aged 70 and over. ${ }^{21}$ The response rate was 97 per cent for the SOA sample for persons 70 years of age and over. Follow up interviews were conducted in 1986, 1988, and 1990 using computer assisted telephone interviewing (CATI) and mail questionnaires. In 1986, because of budget constraints, a subsample (5151) was surveyed. Matching to the National Death Index (NDI) and Medicare files was done to derive the best estimate of the deceased. Because the focus of this study is on self reports of health, only self respondents $(90 \%$ of the study sample) were included in subsequent analyses.

\section{MEASUREMENT}

The dependent variables considered in this study were mortality and functional change. Duration of survival was calculated as the interval between the date of baseline interview in 1984 and date of death occurring by the end of 1991 . A total of 2870 persons (38\% of baseline respondents) died during the follow up period. Of the 6780 self respondents 2431 died.

Table 1 Bivariate associations of the elderly's self assessed health in 1984 with six year functional decline and seven year mortality

\begin{tabular}{|c|c|c|}
\hline Self assessed health & Functional decline ${ }^{\star}$ & Mortalityt \\
\hline \multicolumn{3}{|l|}{ General health } \\
\hline \multicolumn{3}{|l|}{ Global health } \\
\hline Excellent & 1.00 & 1.00 \\
\hline Very good & $1.45(1.20,1.75)$ & $1.13(0.99,1.28)$ \\
\hline Good & $1.89(1.55,2.30)$ & $1.42(1.23,1.63)$ \\
\hline Fair/poor & $2.70(2.21,3.30)$ & $2.13(1.83,2.48)$ \\
\hline \multicolumn{3}{|l|}{ Taking care of health } \\
\hline Excellent & 1.00 & 1.00 \\
\hline Very good & $1.44(1.19,1.74)$ & $1.21(1.08,1.36)$ \\
\hline Good & $1.69(1.38,2.07)$ & $1.44(1.29,1.61)$ \\
\hline Fair/poor & $2.77(2.11,3.63)$ & $1.63(1.39,1.92)$ \\
\hline \multicolumn{3}{|l|}{ Worry over health } \\
\hline Not at all & 1.00 & 1.00 \\
\hline Hardly any & $1.18(0.98,1.42)$ & $0.93(0.79,1.09)$ \\
\hline Some & $1.56(1.32,1.86)$ & $1.33(1.18,1.49)$ \\
\hline Great deal & $1.72(1.27,2.32)$ & $1.90(1.68,2.16)$ \\
\hline \multicolumn{3}{|l|}{ Control over future health } \\
\hline A great deal & 1.00 & 1.00 \\
\hline Some control & $1.44(1.25,1.65)$ & $1.21(1.10,1.34)$ \\
\hline None/very little & $1.56(1.24,1.98)$ & $1.59(1.42,1.78)$ \\
\hline \multicolumn{3}{|c|}{ Physical health } \\
\hline \multicolumn{3}{|c|}{ Physical activity relative to peers } \\
\hline A lot more active & 1.00 & 1.00 \\
\hline More active & $1.20(0.98,1.47)$ & $1.17(1.02,1.33)$ \\
\hline About as active & $1.69(1.44,2.00)$ & $1.48(1.35,1.64)$ \\
\hline Less active & $2.17(1.58,3.00)$ & $2.69(2.40,3.07)$ \\
\hline \multicolumn{3}{|l|}{ Getting exercise } \\
\hline As much as needed & 1.00 & 1.00 \\
\hline Less than needed & $1.39(1.20,1.62)$ & $1.43(1.31,1.56)$ \\
\hline \multicolumn{3}{|c|}{ Mental health } \\
\hline \multicolumn{3}{|l|}{ Trouble remembering things } \\
\hline Never & 1.00 & 1.00 \\
\hline Rarely & $0.89(0.69,1.13)$ & $0.93(0.82,1.05)$ \\
\hline Sometimes/frequently & $1.21(1.01,1.45)$ & $0.97(0.88,1.06)$ \\
\hline \multicolumn{3}{|l|}{ Frequency getting confused } \\
\hline Never & 1.00 & 1.00 \\
\hline Rarely & $1.08(0.90,1.29)$ & $1.13(1.02,1.26)$ \\
\hline Sometimes/frequently & $1.70(1.40,2.06)$ & $1.25(1.12,1.39)$ \\
\hline
\end{tabular}

*Age and gender adjusted odds ratios with $95 \%$ confidence intervals. Change in disability level (none, IADLs only, 1-2 ADLs, 3-5 ADLs) between 1984 and 1990 coded as $0=$ no change/improvement, 1=deterioration. +Age and gender adjusted hazard ratios with $95 \%$ confidence intervals.
Disability was defined as a composite index of activities of daily living (ADLs) and instrumental activities of daily living (IADLs) scales. ADLs included items asking about difficulty bathing, dressing, eating, transferring, and toileting; and IADLs included preparing meals, shopping for personal items, managing money, using the telephone, doing heavy housework, and doing light housework. Limitations in ADLs (or IADLs) were defined as having difficulty with and receiving help from another person or unable to do in one or more of the items. Disability levels were categorised as none (not disabled), mild (IADLs only), moderate (1-2 ADLs), and severe (3-5 ADLs). A hierarchical scale including IADL and ADL has been shown to have discriminant and predictive validity for functional ability and mortality. ${ }^{22}$ Changes in disability levels were dichotomised into decline $(=1$, if disability level in 1990 increased relative to baseline level in 1984) or no change/improvement $(=0$, if disability level in 1990 decreased or remain unchanged compared with that of baseline).

The independent variables were self reported general, physical, and mental health status: four items related to general health, and two items each on physical health and mental health. Self reports of general health included the standard item on global health status, "Would you say your health in general is excellent, very good, good, fair, or poor?" Also, included were items on taking care of health ("How good a job do you feel you are doing in taking care of your health? Would you say excellent, very good, good, fair, or poor?"); worry over health ("During the past year, has your overall health caused you a great deal of worry, some worry, hardly any worry, or no worry at all?); and control over future health ("How much control do you think you have over your future health? Would you say you have a great deal of control, some, very little, or none at all?").

Self reported physical health assessed levels of physical activity ("Compared to other people your age, would you say you are physically more active, less active, or about as active?" and exercise ("Do you feel that you get as much exercise as you need, or less than you need?"). On mental health, participants were asked about frequency of memory problems ("In the past year, about how often did you have trouble remembering things-frequently, sometimes, rarely, or never?" and confusion ("In the past year, about how often did you get confused-frequently, sometimes, rarely, or never?").

Control variables included were sociodemographic characteristics (age, gender, race, marital status, education, income, living arrangements, and Medicaid insurance status); functional status, medical conditions, and utilisation of health services and social support services. Functional status variables included disability level, as described previously, as well as number of difficulty with upper body functioning (reaching up over your head, reaching out, using fingers to grasp or handle, lifting or carrying 25 pounds and 10 pounds) and 
lower body functioning (walking for a quarter of a mile; walking up 10 steps without resting; standing or being on your feet for two hours; sitting for two hours; and stooping, crouching, or kneeling). Subjects were asked about a history of hypertension, coronary heart disease, stroke, broken hip, or cancer. Also, presence of arthritis, diabetes or falls in the past 12 months were assessed. Health services utilisation was measured by number of doctor visits and hospital days during the past 12 months.

For measures of social support and services use, amount of social activity and level of satisfaction with social activity were assessed. Amount of social activities during the past two weeks were categorised into three groups $(0-1$, $2-4,5-6)$ based on the six items: get together with friends or neighbours; talk on telephone with friends or neighbours; get together with relatives; talk with relatives on telephone; go to church or temple; and go to movies, sports events, etc. Respondents were also asked about their feelings toward present social activities, whether they are doing enough, too much, or would like to do more. Number (none, 1, 2-9) of community services used dealt with a broad range of services: senior centre, special transportation for elderly, meals delivered to house, meals in senior centre, homemaker service, telephone call-check service, visiting nurse service, health aide, and adult day care.

\section{ANALYSES}

The effects of each of the eight measures of self reported general, physical, and mental health on functional decline and mortality were analysed. Adjusting for age and gender, multiple logistic regression was used in assessing functional decline, and Cox proportional hazard model for mortality. Then all eight self reported health measures were incorporated in the model to identify the independent contribution of each in predicting future health outcomes. In modelling relations among potential confounding variables and functional decline and mortality, $\chi^{2}$ tests were used to identify significant correlates to control for. Control variables not found to be significantly related were excluded in the final model, except when it was considered important to control for. To examine gender differences in the predictive value of self assessments of health, subgroup analyses were performed. In all analyses, SUDAAN software was used to take into account design effects, oversampling, and non-response because of multi-stage sampling design of the survey. $^{23}$

Table 2 Predictors of functional decline* in older adults-multiple logistic regression analyses with odds ratios and $95 \%$ confidence intervals

\begin{tabular}{|c|c|c|c|}
\hline Variable & OR $(95 \% C I)$ & Variable & OR $(95 \% C I)$ \\
\hline Self assessed health & & Marital status & \\
\hline Global health status & & Married & 1.00 \\
\hline Excellent & 1.00 & Widowed & $0.60(0.29,1.24)$ \\
\hline Very good & $1.20(0.99,1.46)$ & Not married & $0.39(0.18,0.84)$ \\
\hline Good & $1.43(1.16,1.76)$ & Living arrangements & \\
\hline Fair/poor & $1.56(1.20,2.03)$ & With spouse & 1.00 \\
\hline Taking care of health & & With non-/relative & $2.08(1.01,4.26)$ \\
\hline Excellent & 1.00 & Living alone & $1.68(0.82,3.44)$ \\
\hline Very good & $1.18(0.94,1.47)$ & Functioning & \\
\hline Good & $1.18(0.93,1.49)$ & Upper body limitation & \\
\hline Fair/poor & $1.67(1.20,2.33)$ & None & 1.00 \\
\hline Worry over health & & $1-2$ & $1.33(1.06,1.66)$ \\
\hline Not at all & 1.00 & $3-5$ & $1.32(0.89,1.96)$ \\
\hline Hardly any & $1.03(0.85,1.26)$ & Lower body limitation & \\
\hline Some & $1.03(0.83,1.27)$ & None & 1.00 \\
\hline Great deal & $1.02(0.67,1.54)$ & $1-2$ & $1.46(1.19,1.79)$ \\
\hline Control over health & & $3-5$ & $1.74(1.28,2.37)$ \\
\hline A great deal & 1.00 & Disease/conditions & \\
\hline Some & $1.10(0.92,1.32)$ & Ever had: & \\
\hline None/very little & $1.07(0.83,1.39)$ & Hypertension & \\
\hline Physical activity & & No & 1.00 \\
\hline A lot more active & 1.00 & Yes & $1.30(1.09,1.56)$ \\
\hline More active & $0.99(0.80,1.23)$ & In past 12 months: & \\
\hline About as active & $1.29(1.08,1.55)$ & Diabetes & \\
\hline Less active & $1.65(1.14,2.39)$ & No & 1.00 \\
\hline Getting exercise & & Yes & $1.48(1.12,1.95)$ \\
\hline As much as needed & 1.00 & Falls & \\
\hline Less than needed & $1.17(0.99,1.38)$ & No & 1.00 \\
\hline Trouble remembering & & Yes & $1.28(1.05,1.57)$ \\
\hline Never & 1.00 & Amount of social activity $\dagger$ & \\
\hline Rarely & $0.83(0.64,1.07)$ & $0-1$ & 1.00 \\
\hline Sometimes/frequently & $0.90(0.73,1.11)$ & $2-4$ & $0.76(0.52,1.10)$ \\
\hline Getting confused & & $5-6$ & $0.63(0.42,0.95)$ \\
\hline Never & 1.00 & Use of services & \\
\hline Rarely & $0.99(0.80,1.22)$ & Doctor visits & \\
\hline Sometimes/frequently & $1.35(1.09,1.66)$ & None & 1.00 \\
\hline Sociodemographics & & $1-2$ & $1.44(1.12,1.84)$ \\
\hline Age in 1984 & & $3-6$ & $1.25(0.96,1.64)$ \\
\hline $70-74$ & 1.00 & $7+$ & $1.42(1.06,1.91)$ \\
\hline $75-79$ & $1.98(1.66,2.38)$ & & \\
\hline $80-84$ & $3.69(2.88,4.73)$ & & \\
\hline $85+$ & $9.08(6.38,12.93)$ & & \\
\hline
\end{tabular}

Controlling for baseline disability level in 1984. Gender, race, education, poverty index, stroke, use of community services, hospital days have been controlled. ${ }^{\star}$ Change in disability level between 1984 and 1990 coded as $0=$ no change/improvement, $1=$ decline. †Total number of activities in the past two weeks among the following: (1) get together with friends or neighbours; (2) talk on telephone with friends or neighbours; (3) get together with relatives; (4) talk with relatives on telephone; (5) go to church or temple; and (6) go to movies, sports events, etc. 
Results

Overall, self reports covering broad dimensions of health were significantly associated with functional decline and mortality (table 1). Persons who tended to assess their health more negatively were at a higher risk of experiencing decline in functioning as well as death. Age and gender adjusted risks of six year functional decline were strongly predicted by self rated global health and self care ability (taking care of one's health), with elderly persons who rated fair or poor showing almost three times the risk compared with those who rated excellent. Elderly people who reported to be less physically active relative to peers were twice more likely $(\mathrm{OR}=2.17,95 \% \mathrm{CI}: 1.58,3.00)$ to experience deterioration in functioning than those who reported to be a lot more active. Having problems of memory and cognition was also associated with higher risk of functional decline.

A seven year mortality risk was also higher among those who reported to be in low health, across all items on general health. The hazard ratios were in the range between 1.59 and 2.13 for worse health compared with that of baseline. Being less physically active $(R R=2.69, p<0.001)$ and rating fair/poor on global health $(R R=2.13, p<0.001)$ showed the highest risk of dying. Higher frequency getting
KEY POINTS

- Self assessed global, physical, and mental health measures were predictive of functional decline and mortality in community dwelling older adults.

- Unfavourable self assessment of overall health, self care ability, and physical activity independently contributed to the increased risk of poor health outcomes.

- Gender disparity in the predictive value of self assessments was observed.

confused was also related to increased risk of death. Reports of memory problems, however, were not significant in predicting mortality.

To assess the independent effects of self reported health measures in predicting functional decline and mortality, all eight items were incorporated into regression models. The strength of the association decreased somewhat, but it remained significant in several dimensions. Table 2 shows a multiple logistic regression model on functional decline over a six year period. Even after controlling for baseline disability level and potential confounding variables, self ratings of global health, taking care of health, physical activity, and getting

Table 3 Predictors of seven year mortality in older adults - Cox proportional hazards model with hazard ratios and 95\% confidence intervals

\begin{tabular}{|c|c|c|c|}
\hline Variable & $H R(95 \% C I)$ & Variable & $H R(95 \% C I)$ \\
\hline Self assessed health & & Living arrangements & \\
\hline Global health status & & With spouse & 1.00 \\
\hline Excellent & 1.00 & With non-/relative & $1.23(1.08,1.40)$ \\
\hline Very good & $1.03(0.89,1.20)$ & Living alone & $1.14(1.00,1.30)$ \\
\hline Good & $1.12(0.96,1.32)$ & Functioning & \\
\hline Fair/poor & $1.27(1.06,1.51)$ & Lower body limitation & \\
\hline Taking care of health & & None & 1.00 \\
\hline Excellent & 1.00 & $1-2$ & $1.32(1.17,1.48)$ \\
\hline Very good & $1.19(1.04,1.36)$ & $3-5$ & $1.43(1.22,1.68)$ \\
\hline Good & $1.26(1.11,1.44)$ & Disability level & \\
\hline Fair/poor & $1.04(0.86,1.25)$ & None & 1.00 \\
\hline Worry over health & & IADLs only & $1.06(0.92,1.22)$ \\
\hline Not at all & 1.00 & 1-2 ADLs & $1.25(0.99,1.57)$ \\
\hline Hardly any & $0.84(0.72,0.98)$ & 3-5 ADLs & $1.48(1.05,2.10)$ \\
\hline Some & $0.92(0.81,1.06)$ & Disease/conditions & \\
\hline Great deal & $0.88(0.73,1.05)$ & Ever had: & \\
\hline Control over health & & Hypertension & \\
\hline A great deal & 1.00 & No & 1.00 \\
\hline Some control & $0.98(0.88,1.10)$ & Yes & $1.14(1.04,1.24)$ \\
\hline None/very little & $1.05(0.92,1.21)$ & Stroke & \\
\hline Physical activity & & No & 1.00 \\
\hline A lot more active & 1.00 & Yes & $1.38(1.17,1.62)$ \\
\hline More active & $1.02(0.89,1.18)$ & Cancer & \\
\hline About as active & $1.18(1.05,1.33)$ & No & 1.00 \\
\hline Less active & $1.48(1.22,1.80)$ & Yes & $1.40(1.23,1.59)$ \\
\hline Getting exercise & & In past 12 months: & \\
\hline As much as needed & 1.00 & Arthritis & \\
\hline Less than needed & $1.04(0.94,1.14)$ & No & 1.00 \\
\hline Trouble remembering & & Yes & $0.80(0.73,0.88)$ \\
\hline Never & 1.00 & Diabetes & \\
\hline Rarely & $0.93(0.80,1.07)$ & No & 1.00 \\
\hline Sometimes/frequently & $0.86(0.76,0.96)$ & Yes & $1.38(1.22,1.56)$ \\
\hline Getting confused & & Amount of social activity ${ }^{\star}$ & \\
\hline Never & 1.00 & $0-1$ & 1.00 \\
\hline Rarely & $1.11(1.00,1.23)$ & $2-4$ & $0.89(0.71,1.11)$ \\
\hline Sometimes/frequently & $0.97(0.85,1.10)$ & $5-6$ & $0.70(0.55,0.89)$ \\
\hline Sociodemographics & & Use of services & \\
\hline Age in 1984 & & Hospital days & \\
\hline $70-74$ & 1.00 & None & 1.00 \\
\hline $75-79$ & $1.37(1.22,1.55)$ & $1-9$ & $1.12(0.98,1.28)$ \\
\hline $80-84$ & $1.96(1.71,2.24)$ & $10+$ & $1.37(1.16,1.62)$ \\
\hline $85+$ & $2.91(2.47,3.43)$ & & \\
\hline \multicolumn{4}{|l|}{ Gender } \\
\hline Male & 1.00 & & \\
\hline Female & $0.52(0.47,0.58)$ & & \\
\hline
\end{tabular}

Race, education, poverty index, use of community services, doctor visits have been controlled. $\star$ Total number of activities in the past two weeks among the following: (1) get together with friends or neighbours; (2) talk on telephone with friends or neighbours; (3) get together with relatives; (4) talk with relatives on telephone; (5) go to church or temple; and (6) go to movies, sports events, etc. 
confused remained significantly predictive. In the case of risk for mortality, persons who regarded themselves to be less physically active were almost 50 per cent more at risk compared with those a lot more active (table 3 ). Elderly people who had low ratings of global health, taking care of health, and getting confused had higher risk of death at seven year follow up.

Age was highly predictive of both functional decline and mortality with the oldest old, those 85 and over age group, nine times and three times at higher risk, respectively. Compared with older persons living with a spouse, those living with relatives or others had an increased risk for functional decline and mortality, whereas those living alone showed higher mortality to some degree. Limitations in lower body functioning were significantly $(\mathrm{p}<0.001)$ predictive, with 3-5 limitations exhibiting the highest risk for both functional deterioration $(\mathrm{OR}=1.74)$ and mortality $(\mathrm{R} R=1.43)$. History or presence of diseases or conditions was also predictive of future health outcomes. Hypertension and diabetes increased the risk of functional decline and death. Experience of stroke and cancer were predictive of mortality. Persons who had fallen in the past year were at slightly higher risk of experiencing functional decline $(\mathrm{OR}=1.28, \mathrm{p}<0.05)$, whereas those with arthritis had lower risk of death $(R R=0.80, p<0.001)$. A high amount of social

Table 4 The elderly's self assessed health as predictors of functional decline and mortality by gender

\begin{tabular}{|c|c|c|c|c|}
\hline \multirow[b]{2}{*}{ Self assessed health } & \multicolumn{2}{|c|}{ Functional decline $\neq$} & \multicolumn{2}{|c|}{ MortalityS } \\
\hline & Male & Female & Male & Female \\
\hline \multicolumn{5}{|l|}{ General health } \\
\hline \multicolumn{5}{|l|}{ Global health } \\
\hline Excellent & 1.00 & 1.00 & 1.00 & 1.00 \\
\hline Very good & 1.39 & 1.12 & 0.94 & 1.08 \\
\hline Good & $2.02^{\star \star}$ & 1.24 & 1.12 & 1.09 \\
\hline Fair/poor & $2.85^{\star \star \star}$ & 1.11 & $1.25 \dagger$ & $1.23 \dagger$ \\
\hline \multicolumn{5}{|l|}{ Taking care of health } \\
\hline Excellent & 1.00 & 1.00 & 1.00 & 1.00 \\
\hline Very good & 1.01 & $1.31^{\star}$ & $1.45^{\star \star}$ & 1.01 \\
\hline Good & 1.09 & 1.24 & $1.63^{\star \star \star}$ & 1.02 \\
\hline Fair/poor & 1.09 & $2.37 \star \star \star$ & 1.26 & 0.91 \\
\hline \multicolumn{5}{|l|}{ Worry over health } \\
\hline Not at all & 1.00 & 1.00 & 1.00 & 1.00 \\
\hline Hardly any & 0.96 & 1.09 & $0.81^{\star}$ & 0.89 \\
\hline Some & 0.86 & 1.14 & 0.94 & 0.92 \\
\hline Great deal & 0.93 & 1.17 & 1.05 & $0.81 \dagger$ \\
\hline \multicolumn{5}{|l|}{ Control over future health } \\
\hline A great deal & 1.00 & 1.00 & 1.00 & 1.00 \\
\hline Some control & 1.25 & 1.03 & 0.98 & 1.00 \\
\hline None/very little & 0.83 & 1.23 & 1.11 & 1.02 \\
\hline \multicolumn{5}{|c|}{ Physical health } \\
\hline \multicolumn{5}{|c|}{ Physical activity relative to peers } \\
\hline A lot more active & 1.00 & 1.00 & 1.00 & 1.00 \\
\hline More active & 0.85 & 1.05 & 1.03 & 0.99 \\
\hline About as active & 1.06 & $1.41^{\star \star}$ & 1.17 & $1.18+$ \\
\hline Less active & $2.71^{\star \star}$ & 1.22 & $1.60^{\star \star}$ & $1.40^{\star \star}$ \\
\hline \multicolumn{5}{|l|}{ Getting exercise } \\
\hline As much as needed & 1.00 & 1.00 & 1.00 & 1.00 \\
\hline Less than needed & 1.14 & 1.15 & 1.01 & 1.05 \\
\hline \multicolumn{5}{|l|}{ Mental health } \\
\hline \multicolumn{5}{|c|}{ Trouble remembering things } \\
\hline Never & 1.00 & 1.00 & 1.00 & 1.00 \\
\hline Rarely & 0.81 & 0.86 & $0.82 \dagger$ & 1.02 \\
\hline Sometimes/frequently & 0.85 & 0.94 & $0.78^{\star \star \star}$ & 0.94 \\
\hline \multicolumn{5}{|l|}{ Frequency getting confused } \\
\hline Never & 1.00 & 1.00 & 1.00 & 1.00 \\
\hline Rarely & 1.09 & 0.92 & $1.17 \dagger$ & 1.07 \\
\hline Sometimes/frequently & $1.41 \dagger$ & $1.34^{\star}$ & $0.84 \dagger$ & 1.08 \\
\hline
\end{tabular}

Adjusted for sociodemographic characteristics, functioning, disease/conditions, and use of services (see tables 2 and 3) as well as for each of the self assessed health measures. ‡Adjusted odds ratios. Change in disability level (none, IADLs only, 1-2 ADLs, 3-5 ADLs) between 1984 and 1990 coded as $0=$ no change/improvement, $1=$ deterioration. \$Adjusted hazard ratios. $t \mathrm{p}<0.1,{ }^{\star} \mathrm{p}<0.05$, ${ }^{\star \star} \mathrm{p}<0.01,{ }^{\star \star \star} \mathrm{p}<0.001$ activities significantly reduced the risk for both outcomes. Number of doctor visits was positively associated with functional decline, whereas number of hospital days was with mortality.

There were gender differences in the independent effects of self assessed health on future health outcomes (table 4). In men, poor global health was highly predictive of functional decline, and poor self care ability with mortality. For women, self care ability was predictive of future functioning but not of mortality. Self perceived level of physical activity was a good indictor of future functioning level and mortality in both men and women of older ages. Poor cognitive assessment was related to lower functioning for women only. Higher frequency of experiencing memory problems, however, showed some protective effect for mortality in elderly men.

\section{Discussion}

This study found that self assessed measures of health among the community dwelling elderly are important predictors of functional decline and mortality. Several distinguishing features of this study are: (1) a large nationally representative population of older adults was studied, (2) there was a follow up period of six years for functional decline and seven years for mortality, (3) specific dimensions of self assessed health were examined, and (4) a large number of potential confounders were controlled.

Overall, age and gender adjusted risks for functional decline and mortality were higher for older persons who assessed their general, physical, or mental health less favourably. Among the general health measures, elderly people's assessment of their overall health (global health) was significantly predictive of future levels of functioning and mortality, even after controlling for a number of potential confounders. The results support other studies that found global self rated health to be a consistent predictor of mortality. ${ }^{24}$ It further adds credence to recent studies that suggest this measure to be predictive of future physical functioning. ${ }^{43-15}$

More important, this study found that self care ability (taking care of health) is an independent and significant predictor of both functioning and mortality. This effect was independent of other self reports of health. Bernard et $a l^{18}$ have reported on the predictive value of self ratings of care ability ("How well are you able to take care of yourself at this time?" rated on a scale marked from 0 to 10 ) on mortality in older adults. They, however, point out that they were not able to control for upper and lower body mobility measures because of lack of data. In this study, these functional status measures were controlled for. Greiner $e t \mathrm{al}^{17}$ have also reported "self-rated function" ("Compared to sisters your age, would you say your ability to take care of yourself is excellent, very good, good, fair, or poor?") to be a strong predictor of decline in functioning and increased risk of death. Greiner's study, however, was limited to nuns 75 years or older, whereas 
this study deals with nationally representative community dwelling elderly people 70 years of age and over.

A somewhat surprising finding of gender disparity in the predictive value of self assessed global health and self care ability was observed. For global health, only the older men's assessment of health was significantly predictive of functional decline. Self care ability (taking care of one's health) was a strong predictor of functional decline in women, whereas it was for mortality in men. This suggests that these self assessed health measures are gender sensitive. As people assess their health using various reference points, such as peer group or medical condition, ${ }^{11}{ }^{25}$ this may reflect different ways in which men and women assess their health.

Gender differences in self rated health have been reported in other studies. Hays et al reported significantly increased risk of mortality in men only who rated their health to be poor. In another study, ${ }^{1}$ global self assessed health was significant for both men and women with a higher mortality risk in men than in women who reported poor health. There are, however, studies that suggest otherwise: mortality was higher among women who rated poor health, ${ }^{71}$ and self rated health did not predict mortality in either older men or older women. ${ }^{10}$ Variations in the study population, framing of the question and response formats, variables controlled for, follow up period, and cultural differences may all partially account for the difference in results. These findings point to the need for further research to explain gender disparity in self assessments of health.

The association of older people's perception of their physical activity relative to peers with functional decline and mortality also persisted even after potential confounders were controlled for. There was no gender disparity in this measure in which both men and women who reported about as active or less active than their peers showed an increased risk for functional decline and mortality. Self assessment of physical activity may reflect exercise and active life styles that have been shown to be protective of functional decline, disability, and mortality. ${ }^{26}{ }^{27}$ Wolinsky et $a l^{16}$ have shown that physical activity and exercise are significantly related to mortality and lower body functional change. The benefit of exercise on health outcomes of the elderly has been demonstrated across race, ${ }^{26}$ gender ${ }^{27}$ and regional segment of the population. ${ }^{14}$ This study adds credence to findings of the effect of physical activity and exercise on decreasing the risk of disability and mortality, and suggests the need to focus more attention on health promotion programmes. In concert with prevention efforts, factors affecting physical activity also need to be considered. For instance, disease or conditions may deter a person from being physically active. Social or environmental barriers to stimulating exercise in older persons may be present as well. Further research to identify factors influencing exercise behaviour is warranted.

Measures of self rated mental health, although shown to be predictive of future health outcomes in age and gender adjusted analyses, were relatively less strong as predictors in the multivariate analyses. Increased frequency of getting confused, however, remained predictive of functional decline and mortality. It has been reported that low cognitive function is a risk factor for functional decline in older persons. ${ }^{28}{ }^{29}$ Surprisingly, however, the effects of self reported memory problem and frequency of confusion on mortality appear to be less clear cut, showing a protective effect for "trouble remembering things" and an inverted U shaped pattern for "getting confused." Subgroup analyses showed that these relations were significant for men only. It may be that self reported mental health is not a reliable measure for mortality. Gender disparity in the association calls for further study to understand the mechanisms behind the elderly's self assessment of mental health.

Several study limitations need to be taken into account when interpreting the results. Firstly, a problem common to all longitudinal analysis is differential attrition. It has been reported, however, that in the LSOA, although people of older ages, less educated, who live alone, and persons with poor functioning were more likely to drop out from the survey, non-response caused by loss to follow up did not introduce any significant bias. ${ }^{30}$

Secondly, a lack of control for potential confounding variables may be more of a problem. There is some indication that the relation between self rated health and mortality in older people may be explained by controlling for an "objective" physical health status, such as medical diagnosis given in the physical examination. ${ }^{10}$ Self rated health has been found to be strongly associated with "objective" measures of health, such as the number of diagnoses and self reported symptoms. ${ }^{31}$ Subjective health became non-significant when "objective" health was included in the model. Furthermore, depressive symptoms have been shown to be strongly associated with global self rated health. ${ }^{31}{ }^{32}$ In assessing self reports of mental health, it may be necessary to include depressive symptoms as they seem to predict functioning and other health outcomes in older people. ${ }^{32}$ Also, behavioural risk factors such as smoking and diet were not taken into account because of lack of data. Self assessed physical activity, however, was included in the analysis and shown to be a significant predictor. It is possible that much of the "taking care of health" effect is attributable to health promoting behaviours.

Thirdly, caution should be exercised in interpreting the results pertaining to measurement of functional status. Functioning scale using ADLs and IADLs may not be adequate in detecting changes more complex in nature, such as those related to specific items, for example, changes in bathing, and eating. Instability in these measures over time without real change in status may also be a problem. The analyses did not control for time varying covariates or take into account changes in levels of functioning within the interval of the study period. Thus, time effects cannot be assessed from this study. These issues need to 
be taken into account in future research by using domain specific measures of functioning and making use of multiple year data sets to study time interval changes.

Also, as multiple measures of self assessed health were incorporated in the final model, multicollinearity may be an issue. However, it does not seem to pose a serious problem in this study. Correlations among the eight measures of self reported health were not strong; Pearson correlation coefficients were in the range between 0.08 and 0.39 . Nevertheless this may have affected to some degree the precision of the estimates because of associations and possible interactions among the different dimensions. Attenuation of the predictive strength of self rated health on outcomes may be partially explained by this.

Findings from this study suggest the need for further research into model development and specification to test relations between various self reported health measures and multiple pathways leading to future outcomes. Complex interrelations exist between measures of morbidity, functioning, and self rated health. Johnson and Wolinsky ${ }^{33}$ have demonstrated multidimensional structure of health status through modelling of functioning and health constructs. As a next step in research we need to build and test various models on self rated health as they relate to one another and to other outcomes. Use of path analysis and structural equation modelling to assess the direction and magnitude of direct and indirect effects would be helpful to this end.

This study demonstrates that self assessed global health, as well as, specific dimensions of health act as significant, independent predictors of functioning and mortality in a community dwelling older people. Independent contributions of self rated measures of global health, self care ability, and physical activity were significant even after controlling for other self assessed health measures as well as relevant covariates. Further research needs to be done to assess the validity of self perceived dimension specific health in predicting future health outcomes. Also, the underlying mechanism behind older population subgroup's assessment of health needs to be investigated, given the observed gender disparity in the predictive value of self assessed health. A better understanding of the elderly's self assessment of health will help to improve patient care as well as their long term health outcomes.

This study was initiated during the time the author was a World Health Organisation fellow at the Johns Hopkins University School of Hygiene and Public Health, Baltimore, USA. The author would like to thank anonymous reviewers for their helpful comments.

Conflicts of interest: none.

1 Idler EL, Kasl SV, Lemke JH. Self-evaluated health mortality among the elderly in New Haven, Connecticut, and Iowa and Washington counties, Iowa, 1982-1986. Am I Epidemiol 1990;131:91-103.

2 Kaplan G, Barell V, Lusky A. Subjective state of health and survival in elderly adults. F Gerontol: Soc Sci 1988;43:S11420 .

3 Kaplan GA, Camacho T. Perceived health and mortality: a nine-year follow-up of the Human Population Laboratory cohort. Am f Epidemiol 1983;117:292-304.
4 Mor V, Wilcox V, Rakowski W, et al. Functional transitions among the elderly: patterns, predictors, and related hospiamong the elderly: patterns, predictors, and

5 Mossey JM, Shapiro E. Self-rated health: a predictor of mortality among the elderly. Am $\mathcal{F}$ Public Health 1982;72: $800-8$.

6 Rakowski W, Mor V, Hiris J. The association of self-rated health with two-year mortality in a sample of well elderly. $\mathcal{F}$ Aging Health 1991;3:527-45.

7 Wolinsky FD, Johnson RJ. Perceived health status and mortality among older men and women. $f$ Gerontol: Soc Sci 1992;47:S304-12.

8 Grant MD, Piotrowski ZH, Chappell R. Self-reported health and survival in the Longitudinal Study of Aging, 1984-1986. F Clin Epidemiol 1995;48:375-87.

9 Hays JC, Schoenfeld D, Blazer DG, et al. Global self-ratings of health and mortality: hazard in the North Carolina Piedmont. F Clin Epidemiol 1996;49:969-79.

10 Idler EL, Angel RJ. Self-rated health and mortality in the NHANES-1 Epidemiologic Follow-up Study. Am f Public Health 1990;80:446-52.

11 McCallum J, Shadbolt B, Wang D. Self-rated health and survival: a 7-year follow-up study of Australian elderly. $\mathrm{Am}$ 7 Public Health 1994;84:1100-5.

12 Schoenfeld DE, Malmrose LC, Blazer DG, et al. Self-rated health and mortality in the high-functioning elderly-a closer look at healthy individuals: MacArthur Field Study of Successful Aging. F Gerontol: Med Sci 1994;49:M109-15.

13 Idler EL, Kasl SV. Self-ratings of health: do they also predict change in functional ability? f Gerontol: Soc Sci 1995;50B: S344-53.

14 Kaplan GA, Strawbridge WJ, Camacho T, et al. Factors associated with change in physical functioning in the associated with change in physical functioning in the 140-53.

15 Palmore EB, Burchett BM. Predictors of disability in the final year of life. F Aging Health 1997;9:283-97.

16 Wolinsky FD, Stump TE, Clark DO. Antecedents and consequences of physical activity and exercise among older adults. Gerontologist 1995;35:451-62.

17 Greiner PA, Snowdon DA, Greiner LH. The relationship of self-rated function and self-rated health to concurrent functional ability, functional decline, and mortality: findings from the Nun Study. F Gerontol: Soc Sci 1996;51B: ings from $234-41$.

18 Bernard SL, Kincade JE, Konrad TR, et al. Predicting mortality from community surveys of older adults: the importance of self-rated functional ability. I Gerontol: Soc Sci 1997;52B:S155-63.

19 Kempen GIJM, Miedema I, van den Bos GAM, et al. Relationship of domain-specific measures of health to perceived overall health among older subjects. F Clin Epidemiol 1998; 51:11-18.

20 Kempen GIJM. The MOS Short-Form General Health Survey: single item vs. multiple measures of health-related
quality of life: some nuances. Psychol Rep 1992;70:608-10.

21 Kovar MG, Fitti JE, Chyba MM. The Longitudinal Study of Aging: 1984-1990. Hyattsville, MD: National Center for Aging: 1984-1990. Hya

22 Spector WD, Katz S, Murphy JB, et al. The hierarchical relationship between activities of daily living and instrumental activities of daily living. F Chron Dis 1987;40:481-9.

23 Shah BV, Barnwell BG, Bieler GS. SUDAAN user's manual, release 7.0. Research Triangle Park, NC: Research Triangle Institute, 1996.

24 Idler EL, Benyamini Y. Self-rated health and mortality: a review of twenty-seven community studies. $\mathcal{F}$ Health Soc Behav 1997;38:21-37.

25 Krause NM, Jay GM. What do global self-rated health items measure? Med Care 1994;32:930-42.

26 Clark DO. The effect of walking on lower body disability among older blacks and whites. Am f Public Health 1996;86:57-61

27 Mor V, Murphy J, Masterson-Allen S, et al. Risk of functional decline among well elders. F Clin Epidemiol 1989;42:895-904

28 Gill TM, Williams CS, Richardson ED, et al. Impairments in physical performance and cognitive status as predisposing factors for functional dependence among nondisabled older persons. F Gerontol: Med Sci 1996;51A:M283-88.

29 Greiner PA, Snowdon DA, Schmitt FA. The loss of independence in activities of daily living: the role of low normal cognitive function in elderly nuns. Am 7 Public Health 1996;86:62-6.

30 Mihelic AH, Crimmins EM. Loss to follow-up in a sample of Americans 70 years of age and older: the LSOA 1984-1990. F Gerontol: Soc Sci 1997;52B:S37-48

31 Kivinen P, Halonen P, Eronen M, et al. Self-rated health, physician-rated health and associated factors among elderly men: the Finnish cohorts of the Seven Countries Study. Age Ageing 1998;27:41-7.

32 Mulsant BH, Ganguli M, Seaberg EC. The relationship between self-rated health and depressive symptoms in an epidemiological sample of community-dwelling older adults. F Am Geriatr Soc 1997;45:954-8.

adults. F Am Geriatr Soc 1997;45:954-8.
33 Johnson RJ, Wolinksy FD. The structure of health status among older adults: disease, disability, functional limitation, and perceived health. F Health Soc Behav 1993;34: 105-21. 